\title{
Acid-Sensing Ion Channel 2 Is Important for Retinal Function and Protects against Light-Induced Retinal Degeneration
}

\author{
Mohamed Ettaiche, ${ }^{1}$ Nicolas Guy, ${ }^{1}$ Paul Hofman, ${ }^{2}$ Michel Lazdunski, ${ }^{1}$ and Rainer Waldmann ${ }^{1}$ \\ ${ }^{1}$ Institute of Molecular and Cellular Pharmacology, Centre National de la Recherche Scientifique, Unité Mixte de Recherche 6097, Sophia-Antipolis, 06560 \\ Valbonne, France, and 'Faculty of Medicine, Institut National de la Santé et de la Recherche Médicale EPI 02-15, Immunité des Muqueuses et Vaccination, \\ 06107 Nice Cedex, France
}

\begin{abstract}
$\mathrm{pH}$ variations in the retina are thought to be involved in the fine-tuning of visual perception. We show that both photoreceptors and neurons of the mouse retina express the $\mathrm{H}^{+}$-gated cation channel subunits acid-sensing ion channel 2a (ASIC2a) and ASIC2b. Inactivation of the ASIC2 gene in mice leads to an increase in the rod electroretinogram a- and b-waves and thus to an enhanced gain of visual transduction. ASIC2 knock-out mice are also more sensitive to light-induced retinal degeneration. We suggest that ASIC2 is a negative modulator of rod phototransduction, and that functional ASIC2 channels are beneficial for the maintenance of retinal integrity.
\end{abstract}

Key words: proton-gated channels; ASIC2; vision; rods; acid; neurotransmission; retinal degeneration

\section{Introduction}

Fluctuations in extracellular $\mathrm{pH}$ are not only associated with pathological conditions such as ischemia but also occur in healthy organisms during neurotransmission and in the vicinity of metabolically active cells. Neurons dispose of a particular family of ion channels, $\mathrm{H}^{+}$-gated cation channels, that is activated by extracellular acid. Several subunits of those acid-sensing ion channels (ASICs) were cloned during the past years (GarciaAnoveros et al., 1997; Lingueglia et al., 1997; Waldmann et al., 1997a; Waldmann and Lazdunski, 1998; Akopian et al., 2000). ASICs are mainly expressed in the CNS and PNS, where they form homomultimeric and heteromultimeric cation channels. ASICs in the CNS could sense local pH fluctuations associated with the release of acidic synaptic vesicles (Miesenbock et al., 1998) and modulate neuronal excitability. Acid sensing is also involved in several facets of sensory perception, where a role of ASICs is suggested. Tissue acidosis accompanies many painful pathologies such as ischemia and inflammation (Steen et al., 1995). ASICs are expressed in sensory neurons, and it is likely that ASICs are involved in the perception of pain or nociception associated with those pathologies (Krishtal and Pidoplichko, 1981; Waldmann et al., 1997b; Benson et al., 1999; Sutherland et al., 2001; Voilley et al., 2001; Chen et al., 2002). Perception of sour taste also means sensing acids. ASICs are expressed in taste cells and might be the acid sensors involved in the perception of sour taste (Waldmann et al.,

\footnotetext{
Received May 21, 2003; revised Dec. 1, 2003; accepted Dec. 2, 2003.

This work was supported by the Centre National de la Recherche Scientifique and the Association Française contre les Myopathies. We thank Dr. Christophe Laigle for the examination of the cerebellar blood flow.

Correspondence should be addressed to Michel Lazdunski, Institut de Pharmacologie Moléculaire et Cellulaire, Centre National de la Recherche Scientifique, Unité Mixte de Recherche 6097, 660 Route des Lucioles, SophiaAntipolis, 06560 Valbonne, France. E-mail: ipmc@ipmc.cnrs.fr.

D0I:10.1523/JNEUROSCI.4698-03.2004

Copyright $\odot 2004$ Society for Neuroscience $\quad 0270-6474 / 04 / 241005-08 \$ 15.00 / 0$
}

1997a; Liu and Simon, 2001; Lin et al., 2002). In addition to a role in acid sensing, an involvement of ASICs in mechanosensation has also been proposed (Price et al., 2000, 2001).

Recent data suggest that $\mathrm{pH}$ fluctuations also play an important role in the retina, where acidic transients are involved in the fine tuning of visual perception. Protons that are coreleased with glutamate into photoreceptor ribbon synapses act as feedback inhibitors of $\mathrm{Ca}^{2+}$ channels and thus transmitter release (Barnes et al., 1993; DeVries, 2001). Furthermore, the $\mathrm{pH}$ of the retina follows a circadian rhythm (Dmitriev and Mangel, 2001), and $\mathrm{pH}$ changes might play a role in the adaptation of the retinal responses to different light intensities. This led us to examine the presence and functional role of ASIC2 in the retina. We show that photoreceptors and neurons in the retina express the ASIC2 splice variants ASIC2a and ASIC2b. Inactivation of the ASIC2 gene increases the light response of the retina and sensitizes the mouse retina toward light-induced degeneration.

\section{Materials and Methods}

Generation of conditional ASIC2 knock-out mice. Mouse genomic 129SvJ bacterial artificial chromosome (BAC) grids (Genome Systems, St. Louis, $\mathrm{MO}$ ) were hybridized with the ASIC2 coding sequence, and positive BACs were analyzed. The genomic fragments were subcloned into a targeting vector backbone (see Fig. 1 for the strategy). Transfection and antibiotic selection of embryonic stem cells, blastocyst injection, and breeding of mice carrying the homologous recombination were performed as described previously (Stewart, 1993; Szabo and Mann, 1994). To inactivate the targeted ASIC2 gene, mice were crossed with mice expressing Cre recombinase driven by the cytomegalovirus promoter. Unless indicated otherwise, we used 129Sv mice backcrossed for six generations with C57BL/6 mice.

Quantitative PCR. cDNA was prepared from retina total RNA and quantitative real-time PCR (TaqMan) was performed using glyceraldehyde-3-phosphate dehydrogenase (GAPDH) as the standard 
according to the protocols of the supplier of the SYBR Green amplification mix (Eurogentec, Seraing, Belgium) and those of the manufacturer of the equipment (GeneAmp PCR System; Applied Biosystems, Foster City, CA). Each sample was run in three concentrations as duplicates. Data analysis and normalization relative to the GAPDH standard was done using the "relative standard curve technique" according to the Applied Biosystems Prism 7700 Sequence Detection System User Bulletin \#2.

The primers used were ACGGCAAGGAGCTGTCCAT and TTGAACTTCTTGGCCAGGTACTT for ASIC1 and TGAGGCCGTGGAACAAAAG and CCATCTGTCCCCCAATGTCT for ASIC3. The primer pairs amplify all known slice variants of ASIC1 and ASIC3, respectively.

Generation of anti-ASIC2a antibodies and Western blots. Five milligrams of the ASIC2a NH2-terminal peptide MDLKESPSEGSLQPSSC were conjugated to $5 \mathrm{mg}$ of maleimide-activated keyhole limpet hemocyanin (Pierce-Perbio, Bezons, France) according to the manufacturer's protocol. Three rabbits were injected with 200 $\mu \mathrm{g}$ of conjugated peptide in complete Freund's adjuvant and boosted three to six times with $200 \mu \mathrm{g}$ of conjugated peptide in incomplete Freund's adjuvant. The antibodies were affinity-purified with peptide coupled to SulfoLink (Pierce-Perbio). Total protein was prepared from COS-7 (monkey kidney) cells transfected with an ASIC2a expression vector and from dissected mouse retinas. Proteins were separated on $8 \%$ Laemmli gels and transferred to HybondC (Amersham Biosciences, Arlington Heights, IL). The immunolabeling was performed using standard techniques. The first antibody was a 1:200 dilution of affinitypurified anti-ASIC2a antibody, and the second antibody was a 1:10,000-fold diluted peroxidase-labeled anti-rabbit IgG antibody (Amersham Biosciences).

Electron microscopy. Eyes from wild-type and ASIC2 knock-out mice were enucleated and fixed for $24 \mathrm{hr}$ in $2.5 \%$ glutaraldehyde- $4 \%$ paraformaldehyde- $0.1 \%$ sodium cacodylate buffer, $\mathrm{pH}$ 7.4. The anterior part of each eye was removed, and the posterior segments were incubated for 2 $\mathrm{hr}$ in a $1 \%$ aqueous solution of osmium tetroxide and dehydrated by incubation in ascending alcohol concentrations $(50-100 \% ; 10 \%$ increase; 10 min per step). The specimens were then briefly incubated in propylene oxide and left overnight in a 50:50 mixture of propylene oxide and araldite. We prepared ultrathin $(2 \mu \mathrm{m})$ sections using a Leica (Nussloch, Germany) ultracut microtome. Finally, the thin sections were viewed and photographed using a 6100 SEM scanning electron microscope (Jeol, Tokyo, Japan) operating at $80 \mathrm{kV}$.

Histology and in situ hybridization. Twelve-week-old mice were darkadapted overnight. ERGs were recorded to control retinal function. After an additional $2 \mathrm{hr}$ of dark adaptation, the mice were deeply anesthetized with pentobarbital and killed by cervical dislocation. Eyes were removed, punctured at the limbus, and perfused with ice-cold $4 \%$ paraformaldehyde in PBS. After 30 min of fixation, the cornea, the lens, and the vitreous were removed and the fixation of the eyecup was continued in the same medium at $4^{\circ} \mathrm{C}$ for $1 \mathrm{hr}$. The eyecups were cryoprotected in 20\% sucrose in PBS and then embedded into Tissue-Tek (Sakura Finetek, Zoeterwoude, The Netherlands) under frozen isopentane. Frozen sections $(7 \mu \mathrm{m})$ were prepared. For histological examination, the sections were stained with Harry's hematoxylin and eosin. For morphometric analysis, sections that included a full length of the retina approximately along the vertical meridian that passed through the orraserrata and optic nerve head were prepared. The thickness of the outer nuclear layer along the vertical meridian of the superior and inferior retina was measured using a reticule calibrated with a Reichert-Jung micrometer.

For in situ hybridization, the following antisense oligonucleotides were used: ASIC2a, 5' -AGATCTGGATGCTGGAAGGTTGCAGGCTGC-3' ' 5' AGTAGAGGTGTGGCGAAGATCTGGATGCT-3', and 5'-CGCATGCCATGGAGAGTAGAGGTGTTGGCG-3'; ASIC2b, 5'-GGTTCGAGGACCAGGACAACAGCAAGCCAA-3, 5' -CAGTCCTAGCCAGTGGCCCGCGTAGTAGAG-3', and 5'-ACAACAGCAAGCCAAGGGACGTGCAGAAG-3'. A sense oligonucleotide unrelated to ASIC2 (5'-CACAGATGGCTGATGAAAAGCAG-3') was used as a negative control.

The probes were $3^{\prime}$-end-labeled with $\alpha$-digoxigenin (DIG)-UTP by terminal deoxynucleotidyl transferase. The sections were fixed for $20 \mathrm{~min}$ in $4 \%$ paraformaldehyde in PBS, permeabilized in $0.1 \%$ Tween 20 in PBS, and rinsed three times in PBS. The sections were acetylated for 10 min in $0.25 \%$ acetic anhydride and $0.1 \mathrm{M}$ triethanolamine, $\mathrm{pH} 7.5$, prehybridized for $10 \mathrm{~min}$ at $37^{\circ} \mathrm{C}$ in $4 \times$ SSC and $12.5 \%$ formamide, and hybridized overnight at $42^{\circ} \mathrm{C}$ in $4 \times$ SSC, $12.5 \%$ formamide, $2.5 \times$ Denhardt's solution, $250 \mu \mathrm{g} / \mathrm{ml}$ herring sperm DNA, $125 \mu \mathrm{g} / \mathrm{ml}$ yeast tRNA, and $22 \mathrm{ng} / \mu \mathrm{l}$ DIG-labeled probe. The slides were washed briefly with $4 \times$ SSC and then washed for $10 \mathrm{~min}$ with $1 \times$ SSC. DIG-labeled probes were detected according to the protocol from Roche Diagnostics. Briefly, the sections were incubated with anti-DIG-alkaline phosphatase for $2 \mathrm{hr}$ at room temperature, rinsed with $1 \times$ washing buffer, and incubated with nitroblue tetrazolium (NTB)-5-bromo-4-chloro-3-indolyl-phosphate (BCIP) for $2 \mathrm{hr}$ in the dark.

Electroretinography. Three-month-old mice were dark-adapted overnight and subsequently manipulated under dim red light. The mice were anesthetized with ketamine $(66.7 \mathrm{mg} / \mathrm{kg})$ and xylazine $(11 \mathrm{mg} / \mathrm{kg})$ and placed on a heating pad to maintain body temperature near $38^{\circ} \mathrm{C}$. The 

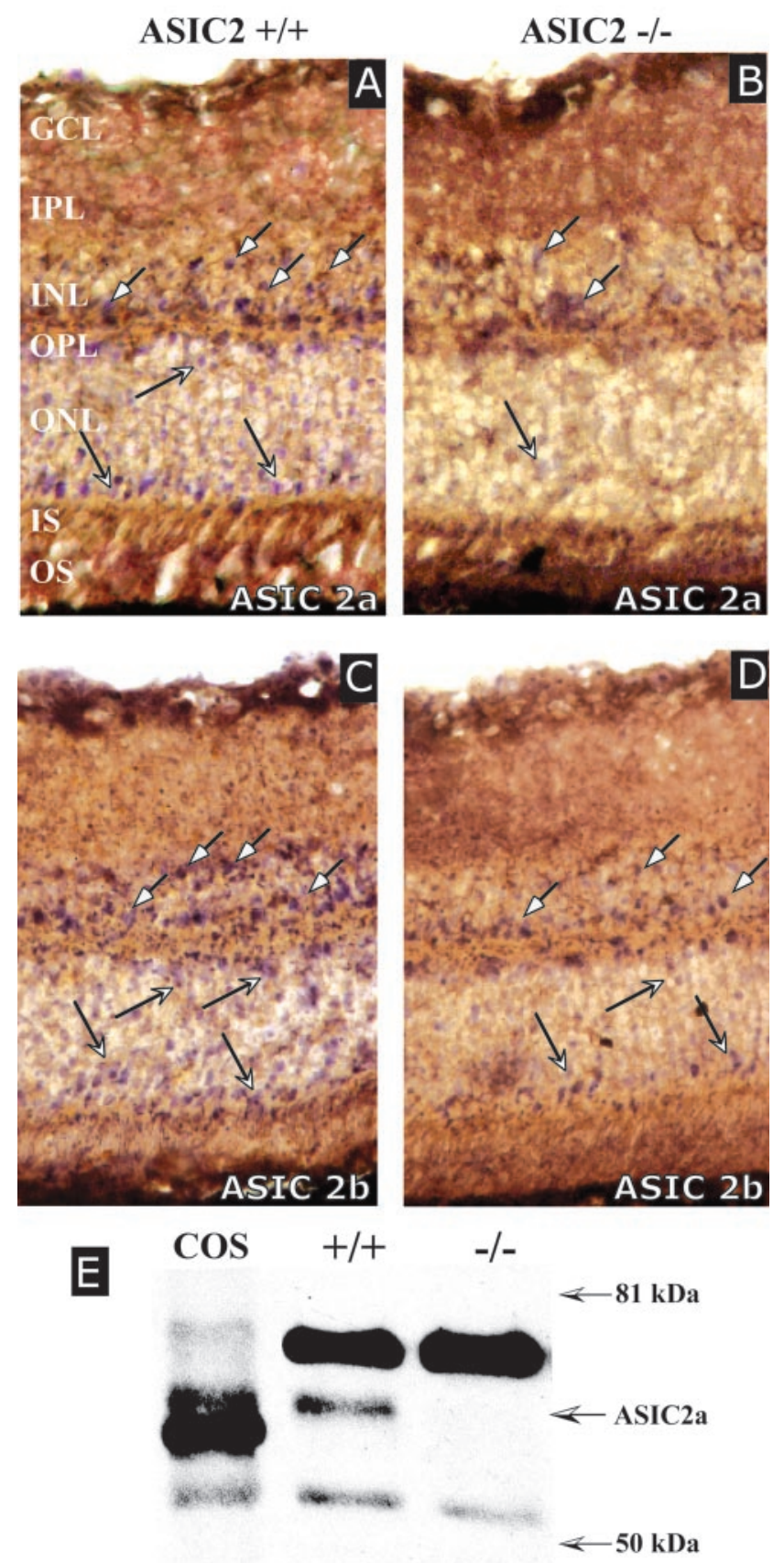

Figure 2. ASIC transcripts and protein in the mouse retina. $A-D$, In situ hybridization with retinas from 3-month-old ASIC2 ${ }^{+/+}(A, C)$ and ASIC2 ${ }^{-1-}(B, D)$ mice with ASIC2a $(A, B)$ or ASIC2b $(C, D)$ probes. In wild-type mice, ASIC2a and ASIC2b mRNAs are expressed in the outer nuclear layer (ONL) and in some cells of the distal and proximal portion of the inner nuclear layer (INL; arrows). Expression of both transcripts was reduced in ASIC2 null mice. Similar results were obtained with three antisense oligonucleotides for each transcript. Both omission of the oligonucleotide and incubation with a DIGlabeled oligonucleotide unrelated to ASIC2 did not yield any labeling. OS, Outer segment; IS, inner segment; $\mathrm{OPL}$, outer plexiform layer; IPL, inner plexiform layer; $\mathrm{GCL}$, ganglion cell layer. $E$, Western blot with an antibody directed against the ASIC2a NH2 terminus confirmed the presence of ASIC2a in the retina. COS, A total of $6 \mu \mathrm{g}$ of homogenate from ASIC2a-transfected COS cells. + I+ and - /- , A total of $20 \mu \mathrm{g}$ of retina homogenate from $\mathrm{ASIC} 2^{+/+}$or $\mathrm{ASIC} 2^{-1-}$ mice. Although a protein of $\sim 60 \mathrm{kDa}$ is labeled in $\mathrm{ASIC2}^{+/+}$mice, neither the $60 \mathrm{kDa}$ protein nor the $7 \mathrm{kDa}$ shorter protein for which the targeted ASIC2 transcript codes is detected in $\mathrm{SIIC}^{-1-}$ mice. The smaller apparent molecular weight of ASIC2 heterologously expressed in COS is probably attributable to a lower glycosylation level. The proteins detected on the blot are recognized by the anti-ASIC2 antibody, because omission of the primary antibody abolished theirlabeling (data not shown). The anti-ASIC2 antibodies that we prepared as well as the commercialized anti ASIC2a-antibodies obtained from Alomone Labs, Chemicon, and AlphaDiagnostics directed against NH2 terminal peptides all cross-react strongly with another protein slightly bigger than $\mathrm{ASIC} 2 \mathrm{a}$ in $\mathrm{ASIC}^{-1-}$ mice.
A
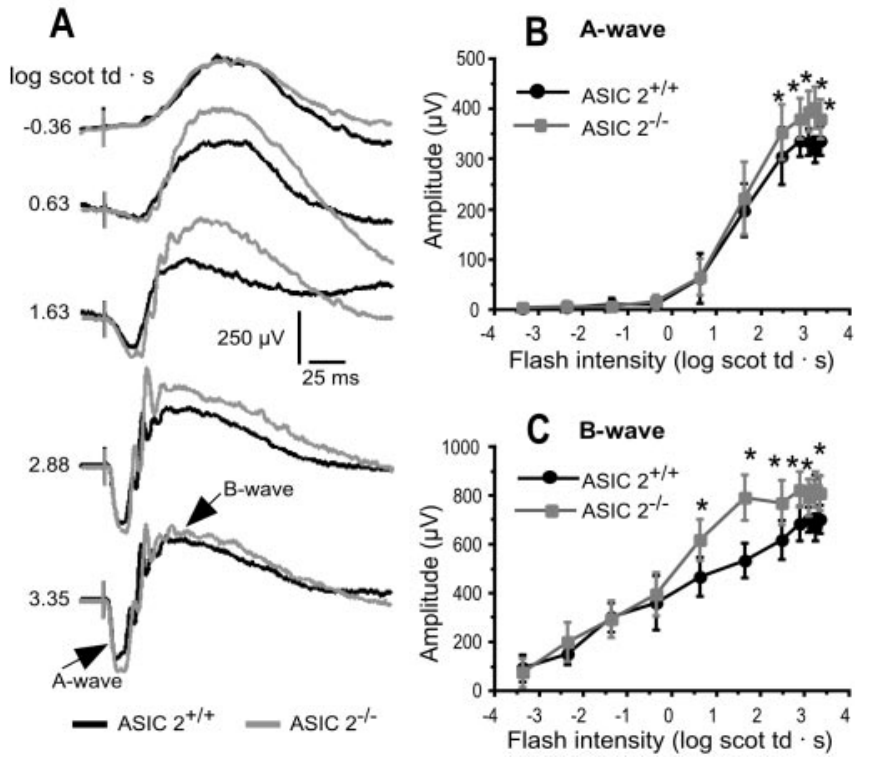

Figure 3. Effect of ASIC2 inactivation on the scotopic ERG. A, Representative ERG traces recorded from 3-month-old $\mathrm{ASIC2}^{+/+}$(gray) and $\mathrm{ASIC}^{-1-}$ (gray) mice at different flash intensities after overnight dark adaptation. Each ERG profile is the average of eight traces from eight mice. $B, C$, Flash intensity-response functions of the full-field ERG a-wave ( $B$ ) and b-wave (C) recorded from $\mathrm{ASIC}^{+1+}$ and $\mathrm{ASIC} 2^{-1-}$ mice. Flash intensities are in scotopic trolands seconds. Each point represent the average of $26 \mathrm{ASIC}^{+/+}$mice or $23 \mathrm{ASIC} 2^{-1-}$ mice. Statistical analysis (two-way ANOVA) of a- and b-wave luminance-response functions indicated a highly significant effect of ASIC2 inactivation $(p<0.0001)$. Asterisks indicate data points with a statistical significant difference ( $p<0.01$; unpaired $t$ test) between wild-type and knock-out mice. Error bars indicate SDs. The effect of ASIC2 inactivation on the ERG a- and b-wave was similar with ketamine-xylazine (shown here) or pentobarbital (data not shown) as the anesthetic.

pupil of the test eye was dilated with $2.5 \%$ neosynephrine and $0.5 \%$ mydriaticum. The mice were kept in the dark for $10 \mathrm{~min}$, and the darkadapted responses (scotopic ERG) were subsequently recorded with an ERG test system (UTAS 2000; LKC Technologies, Gaithersburg, MD), as described previously (Ettaiche et al., 2001). Light stimuli were produced by a Grass PS 22 xenon flash positioned $15 \mathrm{~cm}$ from the eye. Flash intensities were controlled with neutral density filters and calibrated with a radiometer-photometer IL 1700 (International Light, Newburyport, MA). Stimuli were presented in order of increasing intensity and ranged from -3.37 to $3.3 \log$ scotopic trolands•seconds (scot td·sec). The background illumination during the recording of the scotopic ERGs was 1.2 lux. Responses to six successive flashes were averaged. The interflash interval was $15 \mathrm{sec}$ for low stimulus intensities ( $\leq 0.63 \log \operatorname{scot} \mathrm{td} \cdot \mathrm{sec})$ and $30 \mathrm{sec}$ for higher stimulus intensities ( $\geq 1.63 \log \mathrm{scot} t \mathrm{~d} \cdot \mathrm{sec})$. Subsequently, photopic, cone-mediated ERGs were recorded after $10 \mathrm{~min}$ of 30 $\mathrm{cd} / \mathrm{m}^{2}$ background light adaptation. For the recording of photopic ERGs, mice were maintained under anesthesia by boosts with $25 \%$ of the initial dose of anesthetic. Stimuli ranging from -0.36 to $3.3 \mathrm{log}$ scot td·sec were presented at $2.1 \mathrm{~Hz}$ as described previously (Peachey et al., 1993, 1995; Goto et al., 1995), and 50 consecutive responses were averaged.

The amplitude of the a-wave was measured from the prestimulus baseline to the trough of the a-wave. The b-wave amplitude was measured from the trough of the a-wave to the positive peak. Higher stimulus intensities evoked prominent oscillatory potentials, superimposed over the ascending phase of the b-wave ERG.

Effect of light exposure on retinal morphology and function. To determine the effect of exposure to excessive white light on the retina, 3-month-old mice were exposed to constant illumination using a modification of a previously described method (Kayatz et al., 1999; Seiler et al., 2000; Wenzel et al., 2000). The mice were dark-adapted overnight (16 $\mathrm{hr}$ ). Before light exposure, the pupils of both eyes were dilated under dim red light by a topical application of 5\% neosynephrine and $0.5 \%$ mydriaticum. The mice were transferred for $2 \mathrm{hr}$ into acrylic cages that were 


\section{A}
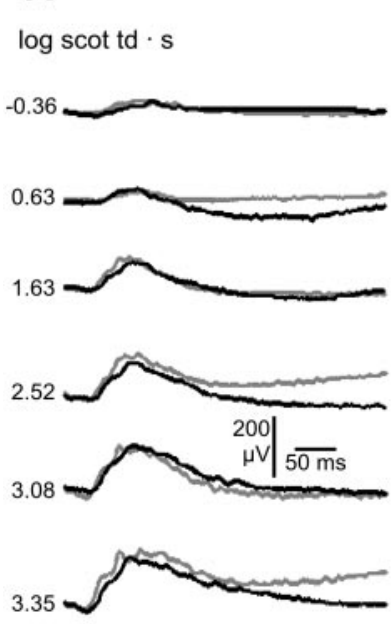

$-\mathrm{ASIC} 2^{+/+}=\operatorname{ASIC} 2^{-/-}$
B A-wave
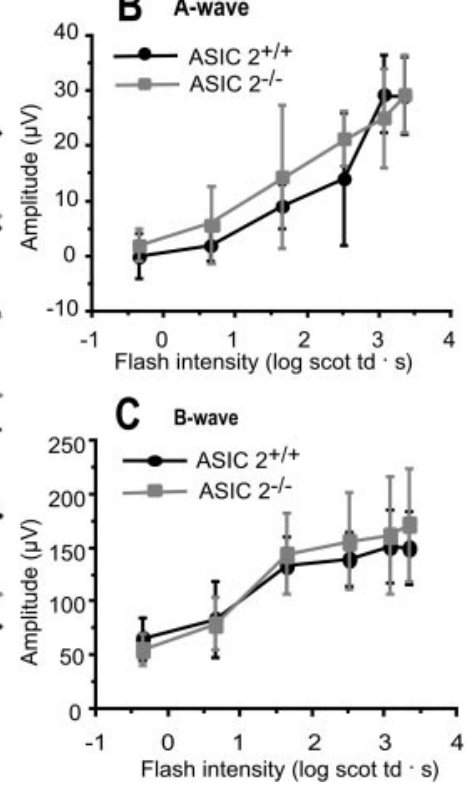

Figure 4. Effect of ASIC2 inactivation on the photopic (cone) ERG. A, Representative ERGs recorded from light-adapted $A S I C 2^{+1+}$ (black) and ASIC2 ${ }^{-1-}$ (gray) mice. Each ERG represents the average of eight traces from eight mice. $B, C$, Flash intensity-response functions of the full-field ERG a-wave $(B)$ and b-wave $(C)$ recorded from 3 -month-old $A S I C 2^{+/+}$and ASIC2 ${ }^{-1-}$ mice after $10 \mathrm{~min}$ of $30 \mathrm{~cd} / \mathrm{m}^{2}$ light adaptation. Flash intensities are in scotopic trolands•seconds. Error bars indicate SDs.

surrounded by fluorescent tubes (daylight $18 \mathrm{~W}$, UV impermeable diffuser; Osram, Berlin, Germany). The maximal intensity measured (Lumacolor II; Tektronix, Les Ulis, France) reached 10 klux in the extreme periphery of the cage and $8 \mathrm{klux}$ at the center. The temperature inside the cage did not exceed $24^{\circ} \mathrm{C}$. Control wild-type and knock-out mice were exposed to 60 lux for $2 \mathrm{hr}$ instead. The mice were subsequently kept for 24 $\mathrm{hr}$ in darkness and returned to the animal facility. ERGs were recorded before illumination and 1,2, and $12 \mathrm{~d}$ later on both eyes using a flash intensity of $3.3 \mathrm{log} \mathrm{scot} t \mathrm{t} \cdot \mathrm{sec}$. Some of the mice were killed after ERG recording, and morphological changes were analyzed as described above.

To identify the cells primarily affected by bright light, eyes from three mice for each experimental condition were removed 24 and $48 \mathrm{hr}$ after the light challenge, $7 \mu \mathrm{m}$ cryosections were prepared, and terminal deoxynucleotidyl transferase-mediated biotinylated UTP nick end labeling (TUNEL)-positive nuclei were detected with the in situ cell death detection-fluorescein kit (Roche Diagnostics) essentially as described previously (Ettaiche et al., 2001). Briefly, sections were fixed in $4 \%$ paraformaldehyde, permeabilized in $0.1 \%$ Tween 20 in PBS, washed in PBS, and incubated with terminal deoxynucleotidyl transferase to incorporated fluorescein nucleotides into DNA strand breaks for $3 \mathrm{hr}$ at $37^{\circ} \mathrm{C}$. Sections were rinsed in PBS and mounted in Vectashield (Vector Laboratories, Burlingame, CA) containing 4',6'-diamino-2-phenylindole (DAPI).

\section{Results}

To inactivate the ASIC2 gene, an exon coding for the second transmembrane domain (TM2), which is crucial for channel activity (Waldmann et al., 1995), was deleted (Fig. 1). The TM2 deletion introduces a frame-shift and truncates both known splice variants of ASIC2, ASIC2a and ASIC2b. The ASIC2 ${ }^{-1-}$ animals were viable, fertile, and did not have any apparent morphological or behavioral abnormalities. There were no differences in cerebellar blood flow (laser Doppler; data not shown); thus ASIC2 inactivation apparently does not affect cardiovascular function. We also compared the relative expression levels of $\mathrm{ASIC} 1$ and ASIC3 in ASIC2 ${ }^{+/+}$and $\mathrm{ASIC} 2^{-1-}$ mice by quanti-

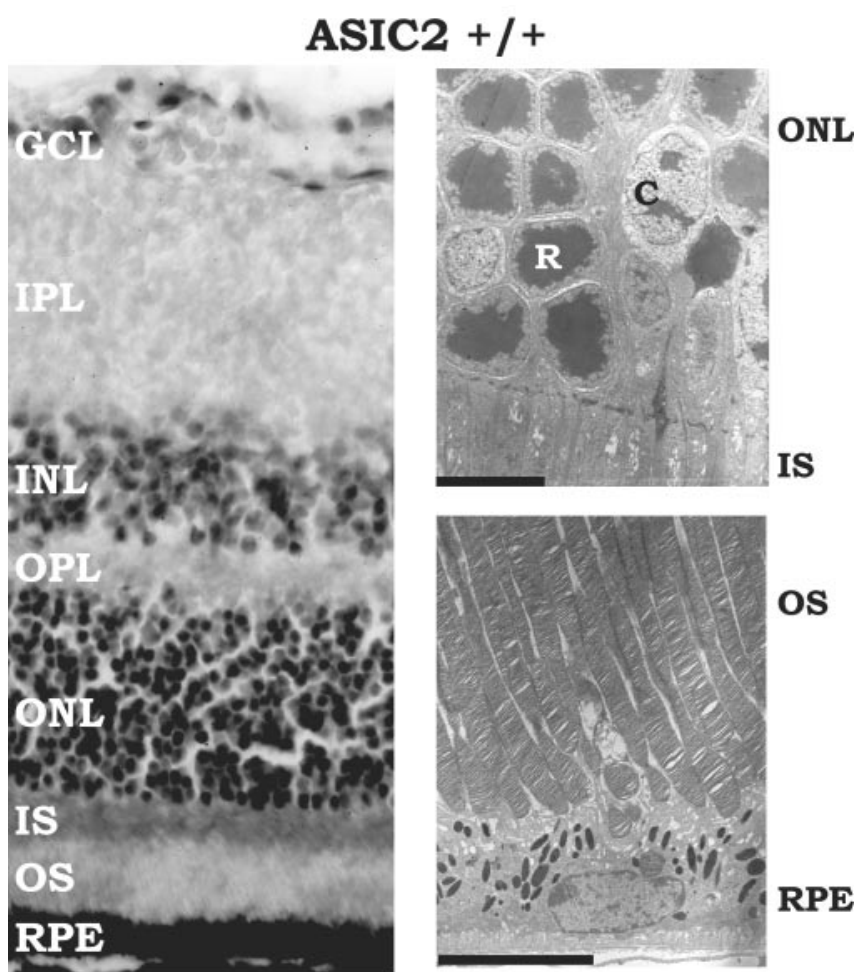

ASIC2 -/-
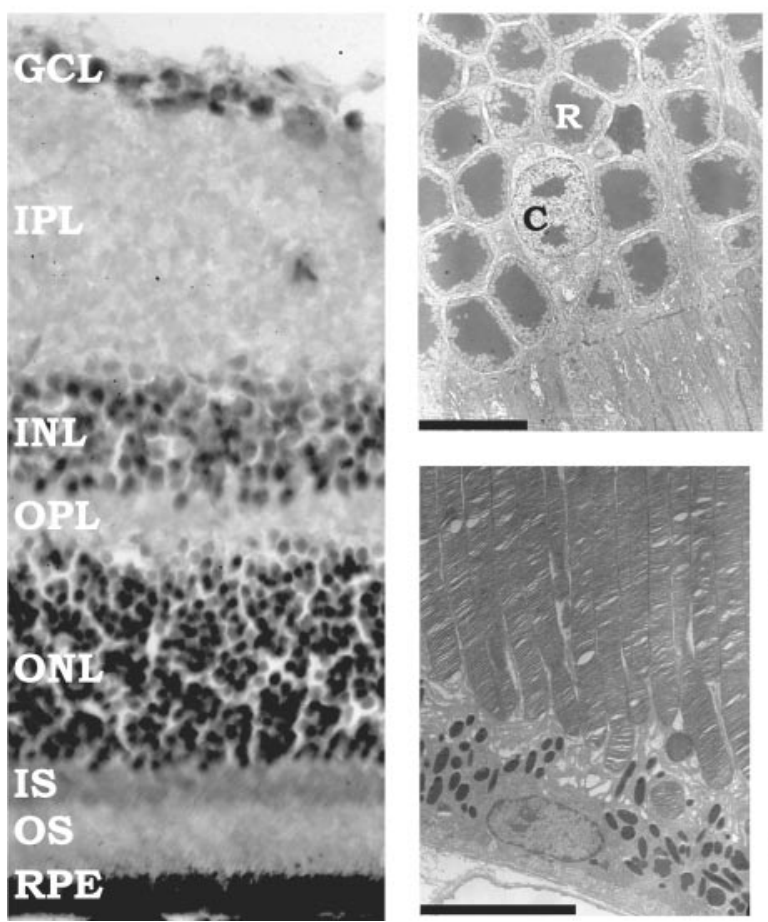

ONL

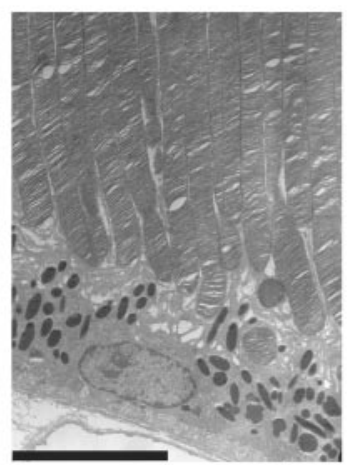

os

Figure 5. The retinal morphology of ASIC2 ${ }^{+/+}$and $\mathrm{ASIC}^{-1-}$ mice is similar. Left, Retinal sections ( $7 \mu \mathrm{m}$ ) from 3-month-old mice stained with Harry's hematoxylin and eosin. There was no difference in inner nuclear layer (INL) and outer nuclear layer (ONL) thickness. The number of rows of perikarya in the inner and outer nuclear layers of the retina of $\mathrm{ASIC}^{+/+}$and ASIC2 ${ }^{-1-}$ mice was similar, and there was no difference in appearance of the rod outer and inner segments between knock-out and wild-type mice. Right, Electron micrographs of $2-\mu \mathrm{m}-$ thick retinal sections. Scale bar, $7 \mu \mathrm{m}$. The retinal pigment epithelium (RPE), outer segments, inner segments, and cell bodies of rods and cones had similar morphologies in ASIC2 ${ }^{+/+}$and ASIC2 ${ }^{-1-}$ mice. GCL, Ganglion cell layer; IPL, inner plexiform layer; OPL, outer plexiform layer; $I S$, inner segment; $0 S$, outer segment; $R$, rod soma; $C$, cone soma. 

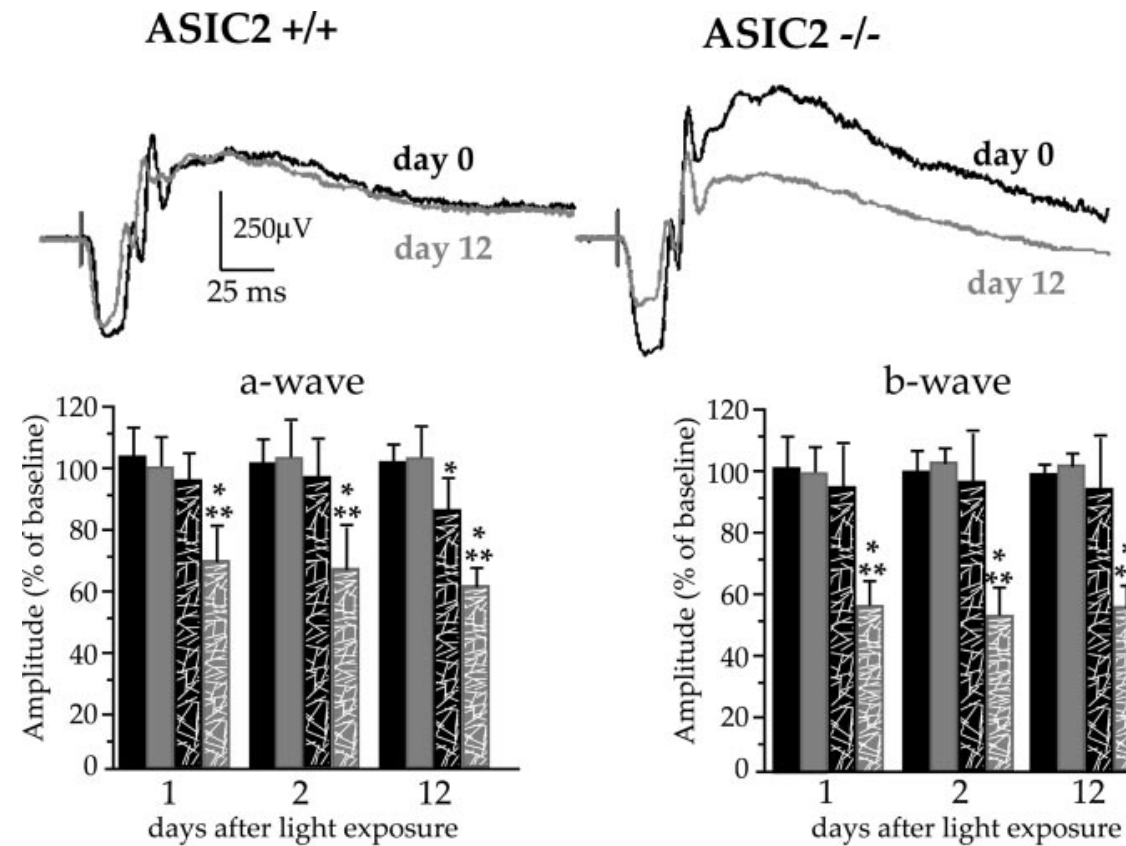

days after light exposure control $+/+\square$ control -/-

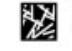

$8 \mathrm{~K}$

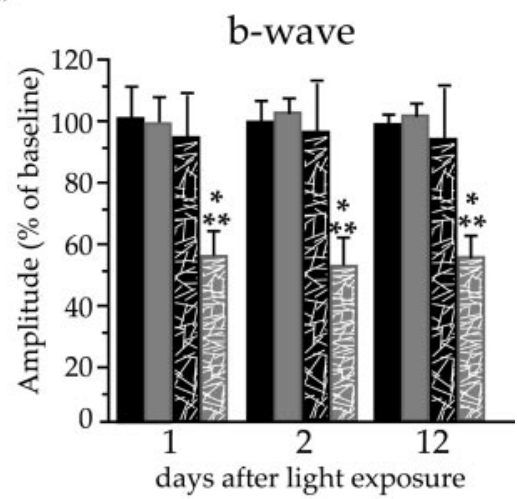

Figure 6. Effect of light exposure on scotopic ERG. Top, ERG traces recorded before illumination and $12 \mathrm{~d}$ after light exposure (8 klux, 2 hr) from ASIC2 ${ }^{+/+}$and ASIC2 ${ }^{-1-}$ mice. Each trace represents the mean of six traces from three mice. Bottom, Effect of a $2 \mathrm{hr} 8$ klux light exposure on the ERG a- and b-wave recorded 1, 2, and $12 \mathrm{~d}$ afterward. Control mice were exposed for $2 \mathrm{hr}$ to 60 lux instead. Values represent percentages (means \pm SD) of the a- or b-wave recorded before light exposure. ${ }^{*} p<0.01$ (Student's unpaired $t$ test) compared with control values recorded before light exposure; ${ }^{* *} p<0.001, \mathrm{ASIC}^{-1-}$ compared with ASIC2 ${ }^{+/+}$exposed to the same light intensity.

tative (TaqMan) PCR. The amount of ASIC1 and ASIC3 transcript was not affected by the ASIC2 knock-out $(p>0.4$; Student's $t$ test; $n=3$ ).

In situ hybridization performed on the retina revealed expression of ASIC2a and ASIC2b mRNA with similar distributions for both splice variants (Fig. 2). Both transcripts were expressed in the outer nuclear layer (photoreceptors) and at a lower level in some cells of the distal and proximal inner nuclear layer.

A Western blot with an anti-ASIC2a antibody directed against the $\mathrm{NH} 2$ terminus showed that ASIC2a protein is expressed in the retina. Although the truncated RNA can still be detected by in situ hybridization (Fig. $2 A$ ), the truncated ASIC2a protein is virtually absent in ASIC2 ${ }^{-1-}$ mice (Fig. $2 B$ ). The anti-ASIC2a antibodies we generated (Fig. $2 B$ ) as well as commercially available antiASIC2a antibodies (Chemicon, Temecula, CA; Alomone Labs, Jerusalem, Israel) (data not shown) all strongly labeled a protein slightly bigger than ASIC2a in both wild-type and ASIC2 knockout mice and were thus not suitable for immunohistochemical localization of ASIC2a.

The expression of ASIC2 in the retina led us to investigate the effect of ASIC2a inactivation on retinal function in vivo by recording of full-field ERGs. Although the ERG waveform was normal for ASIC2 ${ }^{-1-}$ mice, the amplitude of both the a- and the b-wave was significantly increased $(p<0.0001$; two-way ANOVA) in ASIC2 knock-out mice when compared with wildtype mice (Fig. 3). The ERG a-wave is an indicator of the decrease in the dark current circulating between inner and outer segments after photoreceptor activation, whereas the b-wave is thought to be mainly attributable to the activity of bipolar neurons that are postsynaptic to the photoreceptors (Pinto and Enroth-Cugell, 2000).
The increase in the a-wave in $\mathrm{ASIC}^{-1-}$ mice was significant $(0.02>$ $p>0.0001)$ only for high light intensities ( $>2.5 \log \mathrm{scot} \mathrm{td} \cdot \mathrm{sec}$ ). At $2.5 \mathrm{log} \mathrm{scot}$ $\mathrm{td} \cdot \mathrm{sec}$, the mean a-wave amplitude was $306 \pm 57 \mu \mathrm{V}$ in $\mathrm{ASIC} 2^{+/+}$mice and $353 \pm$ $55 \mu \mathrm{V}$ in $\mathrm{ASIC}^{-/-}$mice (Fig. 3), corresponding to an amplitude increase of $\sim 15 \%$ in the knock-out mice. The a-wave is typically small at low light intensities (Fig. 3), and the a-wave and thus potential differences between $\mathrm{ASIC} 2^{+/+}$and ASIC2 $^{-1-}$ mice could be partially masked by the much stronger b-wave. The effect of ASIC2 inactivation on the b-wave (Fig. 3) was greater than the effect on the a-wave and appeared at 100 times lower light intensities $(>0.63 \log \mathrm{scot} t \mathrm{~d} \cdot \mathrm{sec})$. At $1.63 \mathrm{log}$ scot td·sec, the b-wave was $532 \pm 71 \mu \mathrm{V}$ in wild-type mice and $791 \pm 95 \mu \mathrm{V}$ in ASIC2 knock-out mice, corresponding to an amplitude increase of $\sim 48 \%$ in ASIC2 ${ }^{-1-}$ mice (Fig. 3). The increased scotopic ERG $\mathrm{a}-$ and b-waves in ASIC2 ${ }^{-1-}$ mice suggests that ASIC2 activity negatively modulates the gain of the rod pathway.

ASIC2 inactivation did not affect the oscillatory potentials and the kinetics of the $\mathrm{a}$ - and $\mathrm{b}$-waves for all flash intensities tested (Fig. 3). Furthermore, ASIC2 inactivation does not affect the photopic, cone-mediated ERG (Fig. 4). Both the form and the amplitude of the cone a- and b-waves were similar in ASIC2 null and in wild-type mice. However, the mouse retina is more rod-dominated than the human retina (Jeon et al., 1998). Consequently, the photopic ERG signal is low, and small differences between knock-out and wild-type mice might not be visible.

The altered rod phototransduction and neurotransmission of $\mathrm{ASIC} 2^{-1-}$ mice is apparently not attributable to an altered retinal morphology. We could not detect any morphological abnormalities in the retinas of 3-month-old ASIC2 ${ }^{-1-}$ mice (Fig. 5); however, we cannot exclude the possibility that ultrastructural changes in synaptic or nonsynaptic morphology that were not visible on the slices we examined are the cause of the altered ERG in ASIC2 knock-out mice.

The presence of ASIC2 in photoreceptors led us to examine whether the deletion of the ASIC2 gene also renders the retina more vulnerable to light-induced damage. Indeed, an $8 \mathrm{klux}$ light challenge for $2 \mathrm{hr}$ provoked impaired ERG responses (Fig. 6) and more profound retinal damage (Fig. 7) in the absence of ASIC2 channel subunits. With ASIC $2^{+/+}$mice, the light challenge only slightly affected the ERG a-wave $12 \mathrm{~d}$ after light exposure and had no significant effect on the b-wave (Fig. 6). Conversely, illumination strongly affected the electrical activity of ASIC2 ${ }^{-1-}$ retinas (Fig. 6). Just $1 \mathrm{~d}$ after light exposure, the a-wave amplitude was already markedly decreased $(68.76 \pm 10.57 \% ; p<0.01)$ and continued to decline further through day $12(60.05 \pm 5.36 \%$; $p<$ 0.01 ), indicating a permanent impairment of photoreceptor function. Concomitantly, the b-wave decreased to a similar extent (day 1, $57.35 \pm 8.09 \%$; day 12, $55.55 \pm 7.02 \%$; $p<0.01$ ).

Examination of retinas before and after the light challenge revealed that morphological changes are the likely cause of the 


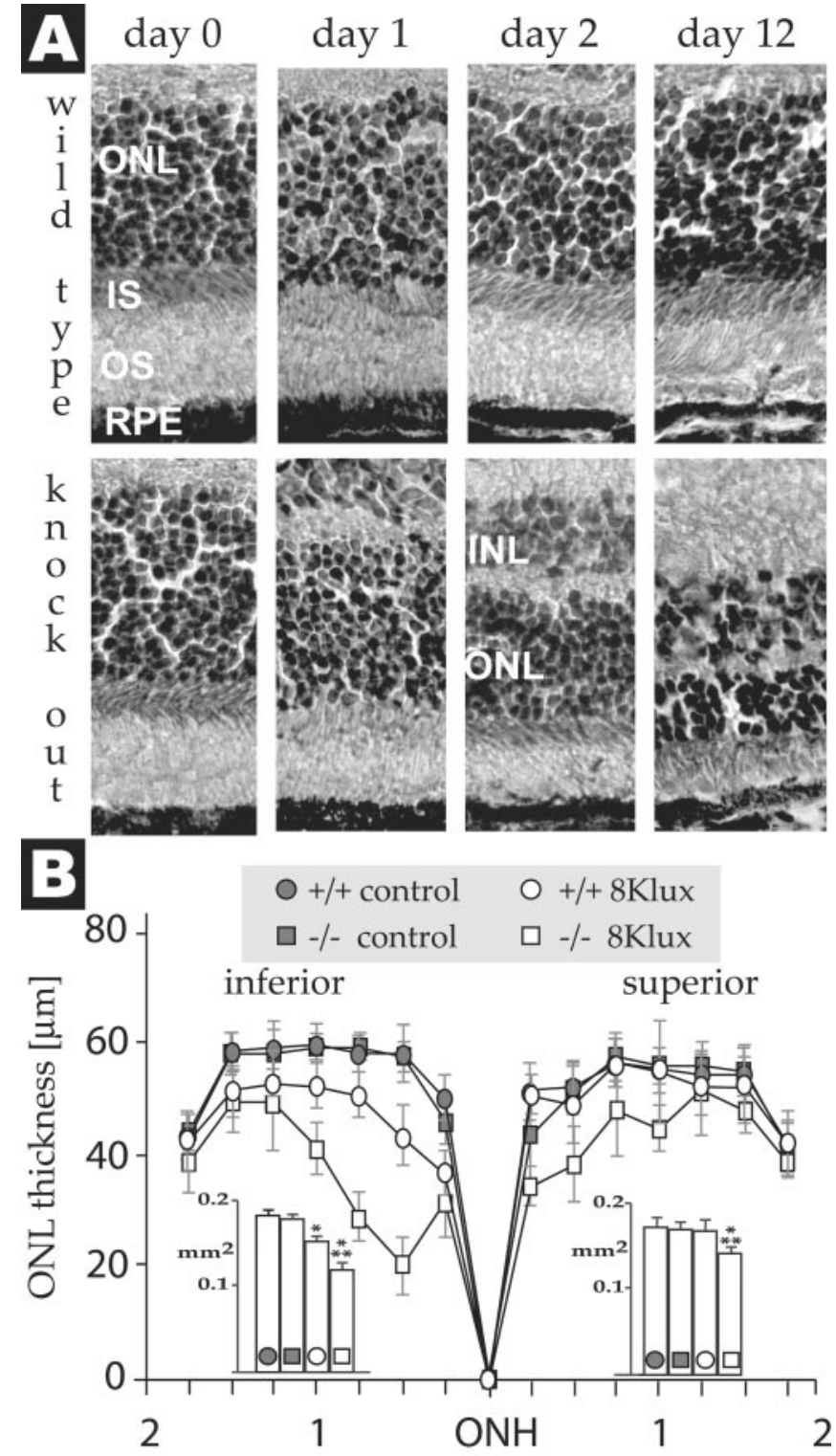

Distance from optic nerve head [mm]

Figure 7. Effect of light exposure on retinal morphology. $A$, Sections of central inferior retina of $\mathrm{ASIC2}^{+/+}$and $\mathrm{ASIC}^{-/-}$mice before and 1, 2, or $12 \mathrm{~d}$ after exposure to 8 klux. ONL, Outer nuclear layer; IS, inner segment; $0 S$, outer segment; RPE, retinal pigment epithelium. $B$, Outer nuclear layer thickness of the superior and inferior retina of $\mathrm{SSIC}^{+/+}$and $\mathrm{ASIC}^{-1-}$ mice $12 \mathrm{~d}$ after a $2 \mathrm{hr} 8 \mathrm{klux}$ light exposure at different distances from the optic nerve head (ONH). Control ASIC2 ${ }^{+/+}$and SSIC2 $^{-1-}$ mice were exposed to 60 lux instead. Points represent means $\pm S D(n=6)$. The inset shows the areas under the curve as means $\pm S D .{ }^{*} p<0.01$ (Mann-Whitney $U$ test) compared with mice of the same genotype that were not exposed to high-intensity light; ${ }^{* *} p<0.01, \mathrm{ASIC}^{-/-}$mice compared with $\mathrm{ASIC2}^{+/+}$mice exposed to the same light intensity.

reduced ERG signal of ASIC2 knock-out mice (Fig. 7). Retinas from wild-type mice showed no obvious damage 1 and $2 \mathrm{~d}$ after the 2 hr 8 klux light challenge compared with control mice that were exposed to 60 lux. A small change in cytoarchitecture and decreased outer nuclear layer thickness of just the central inferior retina was noted after $12 \mathrm{~d}$ (Fig. 7), which is consistent with the slight decrease in the ERG a-wave at that time (Fig. 6). In contrast, retinas of $\mathrm{ASIC} 2^{-1-}$ mice were much more vulnerable to light damage. Outer nuclear layer thinning of the central superior and inferior retina and shortening of rod outer segments appeared $1 \mathrm{~d}$

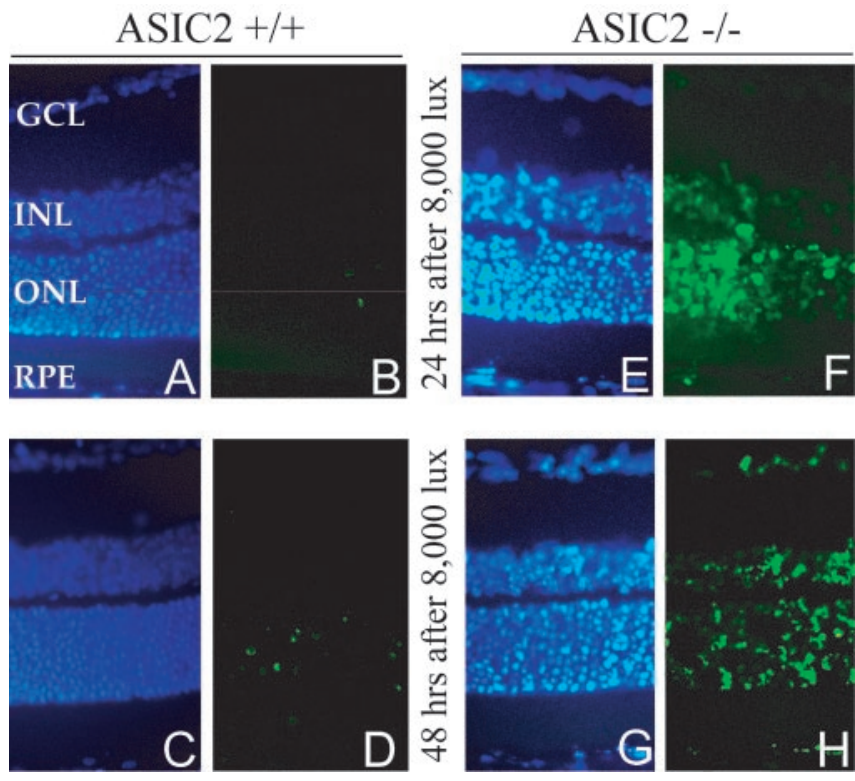

Figure 8. DNA fragmentation after light exposure. Apoptotic cells in retinas of $A S I C 2^{+/+}$ mice $(B, D)$ and $A S I C 2^{-1-}$ mice $(F, H)$ were labeled by in situ end-labeling of fragmented DNA $24 \mathrm{hr}(B, F)$ and $48 \mathrm{hr}(D, H)$ after a $2 \mathrm{hr} 8 \mathrm{klux}$ light exposure. Cells undergoing DNA fragmentation are shown in green. $A, C, E, G$, Blue DAPI fluorescence of chromosomal DNA of the same slices. GCL, Ganglion cell layer; INL, inner nuclear layer; ONL, outer nuclear layer; RPE, retinal pigment epithelium.

after light exposure and increased through day 12. In situ endlabeling of fragmented DNA (Fig. 8) confirmed the increased vulnerability of ASIC2 knock-out mice. Only few TUNELpositive damaged cells were detected in the outer nuclear layer of ASIC $2^{+/+}$mice 24 and $48 \mathrm{hr}$ after a $2 \mathrm{hr}$ exposure to $8 \mathrm{klux}$. Conversely, with ASIC2 ${ }^{-1-}$ mice, light exposure triggered DNA fragmentation in many nuclei of the outer nuclear layer, inner nuclear layer, ganglion cell layer, and retinal pigmented epithelium.

\section{Discussion}

We have shown that inactivation of the ASIC2 gene leads to an important increase in the rod ERG b-wave and to a smaller augmentation of the a-wave. What is the mechanism by which ASIC2 decreases rod ERG responses and affects visual transduction? The only activators of ASIC2 channels known so far are extracellular acidic transients. ASIC2 channels desensitize after activation (Champigny et al., 1998) and are sensors for dynamic pH fluctuations rather than for static acidosis. Rods and cones are metabolically highly active and are the primary source of protons in the retina (Koskelainen et al., 1994). In the inner segments, energy metabolism produces lactic acid and $\mathrm{CO}_{2}$. In the rod outer segments, huge amounts of ATP are consumed mainly for the synthesis of cGMP. According to one study, $\sim 28 \mu \mathrm{M}$ ATP per second and $126 \mu \mathrm{M}$ ATP per second are required for cGMP synthesis in the dark and after illumination, respectively (Ames et al., 1986). Both synthesis of cGMP from GTP and the hydrolysis of cGMP result in the generation of acid because of a net hydrolysis of an ester bond (Koskelainen et al., 1994). Thus local fluctuations in energy consumption, acid production, and extrusion between light and dark might be one mechanism that could create transient, localized $\mathrm{pH}$ changes around photoreceptors after light exposure. $\mathrm{Zn}^{2+}$ is a coactivator of ASIC2a channels (Baron et al., 2001, 2002). Interestingly, this cation is abundant in the retina and changes localization after light exposure (Ugarte and 
Osborne, 1999). Thus fluctuations in both $\mathrm{H}^{+}$and $\mathrm{Zn}^{2+}$ concentrations associated with photoreceptor activity are the most likely activators of ASIC2 channels in photoreceptors. The ERG a-wave represents the drop of the circulating dark current between inner and outer segments of photoreceptors when the cGMP-gated cation channels close after light-stimulated cGMP breakdown (Pinto and Enroth-Cugell, 2000). A possible mechanism for the smaller a-wave in wild-type mice could be an opening of ASIC2 channels in rod outer segments by $\mathrm{pH}$ fluctuations caused by altered rod metabolic activity after light exposure and thus a decreased drop of the circulating current and, as a consequence, a smaller a-wave.

The b-wave, principally an indicator for bipolar neuron activity (Pinto and Enroth-Cugell, 2000), is more strongly affected by ASIC2 inactivation than the a-wave (Fig. 3). This suggests that the altered b-wave is not entirely a consequence of the altered circulating current in photoreceptors, and that ASIC2 channel activity also affects the transmission from rods to bipolar cells or the activity of bipolar neurons. The anti-ASIC2a antibodies that we generated cross-react with other proteins; however, they recognize ASIC2a (Fig. 2) and can be used to show the absence of the protein. Double labeling of retinal slices with our anti-ASIC2 antibody and an anti-protein kinase $\mathrm{C}$ antibody [a marker for bipolar neurons (Greferath et al., 1990)] did not reveal any colocalization (data not shown) on the somata, axons, and axon terminals of bipolar neurons. Thus we currently favor the hypothesis that an altered transmission from rods to bipolar neurons is the cause of the increased b-wave in ASIC $2^{-1-}$ mice. Within the ribbon synapse, huge amounts of glutamate-containing vesicles continuously release their acidic contents into the synaptic cleft during darkness. The resulting acidic transients were shown to modulate the activity of presynaptic voltage-gated $\mathrm{Ca}^{2+}$ channels (Barnes et al., 1993; DeVries, 2001). A possible mechanism for how ASIC2 channel activity could lead to a decreased b-wave is an activation of presynaptic ASIC2 channels in photoreceptors by those $\mathrm{pH}$ fluctuations. The increased $\mathrm{Na}^{+}$influx would provoke a stronger presynaptic depolarization and thus increased glutamate release and activation of postsynaptic metabotropic glutamate receptors. The resulting closure of nonselective cation channels would lead to a reduced activity of bipolar neurons and to a smaller ERG b-wave.

Although those mechanisms for the modulation of the rod ERG by ASIC2 are consistent with the known biophysical properties of ASIC2, ASIC2 modulation of the rod a- and b-wave by other more indirect pathways is also possible. Both localization of the ASIC2 protein and electrophysiological recordings from wild-type and ASIC2 knock-out photoreceptors and retinal neurons will be important additional studies to clarify the mechanism by which ASIC2 affects retinal activity.

The retina is very efficient in the detection of photons over a huge dynamic range. However excessive light exposure can cause severe and irreversible retinal damage. A better knowledge of the pathways involved in light-induced retinal degeneration and of the proteins that alter retinal vulnerability will be crucial for the understanding and treatment of human visual disorders associated with retinal degeneration, such as retinal dystrophies and retinitis pigmentosa. ASIC2 inactivation renders retinas more vulnerable toward light-induced degeneration. As for most other known loss- or gain-of-function mutations that are involved in photoreceptor degeneration, only speculations about the mechanism by which ASIC2 inactivation increases photoreceptor loss are possible at this point. Is it an altered electrical activity of photoreceptors or other more indirect mechanisms that sensitize photoreceptors toward light induced damage? Long-term studies about the mechanisms of light-induced photoreceptor loss in general and on the protective role of ASIC2 channels will be required to clarify the underlying pathways.

ASIC2 is not the only ASIC expressed in the retina. All known ASIC subunits can be detected in the retina by reverse transcription-PCR (Brockway et al., 2002). It is possible that not just ASIC2 but also other ASICs will turn out to be important for the fine tuning of vision and the maintenance of retinal integrity.

\section{References}

Akopian AN, Chen CC, Ding Y, Cesare P, Wood JN (2000) A new member of the acid-sensing ion channel family. NeuroReport 11:2217-2222.

Ames III A, Walseth TF, Heyman RA, Barad M, Graeff RM, Goldberg ND (1986) Light-induced increases in cGMP metabolic flux correspond with electrical responses of photoreceptors. J Biol Chem 261:13034-13042.

Barnes S, Merchant V, Mahmud F (1993) Modulation of transmission gain by protons at the photoreceptor output synapse. Proc Natl Acad Sci USA 90:10081-10085.

Baron A, Schaefer L, Lingueglia E, Champigny G, Lazdunski M (2001) $\mathrm{Zn} 2+$ and $\mathrm{H}+$ are coactivators of acid-sensing ion channels. J Biol Chem 276:35361-35367.

Baron A, Waldmann R, Lazdunski M (2002) ASIC-like, proton-activated currents in rat hippocampal neurons. J Physiol (Lond) 539:485-494.

Benson CJ, Eckert SP, McCleskey EW (1999) Acid-evoked currents in cardiac sensory neurons: a possible mediator of myocardial ischemic sensation. Circ Res 84:921-928.

Brockway LM, Zhou ZH, Bubien JK, Jovov B, Benos DJ, Keyser KT (2002) Rabbit retinal neurons and glia express a variety of ENaC/DEG subunits. Am J Physiol Cell Physiol 283:C126-C134.

Champigny G, Voilley N, Waldmann R, Lazdunski M (1998) Mutations causing neurodegeneration in Caenorhabditis elegans drastically alter the $\mathrm{pH}$ sensitivity and inactivation of the mammalian $\mathrm{H}+$-gated $\mathrm{Na}+$ channel MDEG1. J Biol Chem 273:15418-15422.

Chen CC, Zimmer A, Sun WH, Hall J, Brownstein MJ (2002) A role for ASIC3 in the modulation of high-intensity pain stimuli. Proc Natl Acad Sci USA 99:8992-8997.

DeVries SH (2001) Exocytosed protons feedback to suppress the $\mathrm{Ca}(2+)$ current in mammalian cone photoreceptors. Neuron 32:1107-1117.

Dmitriev AV, Mangel SC (2001) Circadian clock regulation of $\mathrm{pH}$ in the rabbit retina. J Neurosci 21:2897-2902.

Ettaiche M, Heurteaux C, Blondeau N, Borsotto M, Tinel N, Lazdunski M (2001) ATP-sensitive potassium channels (K(ATP)) in retina: a key role for delayed ischemic tolerance. Brain Res 890:118-129.

Garcia-Anoveros J, Derfler B, Neville-Golden J, Hyman BT, Corey DP (1997) $\mathrm{BNaCl}$ and $\mathrm{BNaC} 2$ constitute a new family of human neuronal sodium channels related to degenerins and epithelial sodium channels. Proc Natl Acad Sci USA 94:1459-1464.

Goto Y, Peachey NS, Ripps H, Naash MI (1995) Functional abnormalities in transgenic mice expressing a mutant rhodopsin gene. Invest Ophthalmol Vis Sci 36:62-71.

Greferath U, Grunert U, Wassle H (1990) Rod bipolar cells in the mammalian retina show protein kinase C-like immunoreactivity. J Comp Neurol 301:433-442.

Jeon CJ, Strettoi E, Masland RH (1998) The major cell populations of the mouse retina. J Neurosci 18:8936-8946.

Kayatz P, Heimann K, Schraermeyer U (1999) Ultrastructural localization of light-induced lipid peroxides in the rat retina. Invest Ophthalmol Vis Sci 40:2314-2321.

Koskelainen A, Donner K, Kalamkarov G, Hemila S (1994) Changes in the light-sensitive current of salamander rods upon manipulation of putative $\mathrm{pH}$-regulating mechanisms in the inner and outer segment. Vision Res 34:983-994.

Krishtal OA, Pidoplichko VI (1981) A “receptor" for protons in small neurons of trigeminal ganglia: possible role in nociception. Neurosci Lett 24:243-246.

Lin W, Ogura T, Kinnamon SC (2002) Acid-activated cation currents in rat vallate taste receptor cells. J Neurophysiol 88:133-141.

Lingueglia E, de Weille JR, Bassilana F, Heurteaux C, Sakai H, Waldmann R, Lazdunski M (1997) A modulatory subunit of acid sensing ion channels in brain and dorsal root ganglion cells. J Biol Chem 272:29778-29783. 
Liu L, Simon SA (2001) Acidic stimuli activates two distinct pathways in taste receptor cells from rat fungiform papillae. Brain Res 923:58-70.

Miesenbock G, De Angelis DA, Rothman JE (1998) Visualizing secretion and synaptic transmission with $\mathrm{pH}$-sensitive green fluorescent proteins. Nature 394:192-195.

Peachey NS, Goto Y, al-Ubaidi MR, Naash MI (1993) Properties of the mouse cone-mediated electroretinogram during light adaptation. Neurosci Lett 162:9-11.

Peachey NS, Goto Y, Quiambao AB, al-Ubaidi MR (1995) Functional consequences of oncogene-induced photoreceptor degeneration in transgenic mice. Vis Neurosci 12:513-522.

Pinto LH, Enroth-Cugell C (2000) Tests of the mouse visual system. Mamm Genome 11:531-536.

Price MP, Lewin GR, McIlwrath SL, Cheng C, Xie J, Heppenstall PA, Stucky CL, Mannsfeldt AG, Brennan TJ, Drummond HA, Qiao J, Benson CJ, Tarr DE, Hrstka RF, Yang B, Williamson RA, Welsh MJ (2000) The mammalian sodium channel $\mathrm{BNC1}$ is required for normal touch sensation. Nature 407:1007-1011.

Price MP, Mcllwrath SL, Xie J, Cheng C, Qiao J, Tarr DE, Sluka KA, Brennan TJ, Lewin GR, Welsh MJ (2001) The DRASIC cation channel contributes to the detection of cutaneous touch and acid stimuli in mice. Neuron 32:1071-1083.

Seiler MJ, Liu OL, Cooper NG, Callahan TL, Petry HM, Aramant RB (2000) Selective photoreceptor damage in albino rats using continuous blue light. A protocol useful for retinal degeneration and transplantation research. Graefes Arch Clin Exp Ophthalmol 238:599-607.

Steen KH, Issberner U, Reeh PW (1995) Pain due to experimental acidosis in human skin: evidence for non-adapting nociceptor excitation. Neurosci Lett 199:29-32.
Stewart CL (1993) Production of chimeras between embryonic stem cells and embryos. Methods Enzymol 225:823-855.

Sutherland SP, Benson CJ, Adelman JP, McCleskey EW (2001) Acidsensing ion channel 3 matches the acid-gated current in cardiac ischemiasensing neurons. Proc Natl Acad Sci USA 98:711-716.

Szabo P, Mann JR (1994) Expression and methylation of imprinted genes during in vitro differentiation of mouse parthenogenetic and androgenetic embryonic stem cell lines. Development 120:1651-1660.

Ugarte M, Osborne NN (1999) The localization of free zinc varies in rat photoreceptors during light and dark adaptation. Exp Eye Res 69:459-461.

Voilley N, de Weille J, Mamet J, Lazdunski M (2001) Nonsteroid antiinflammatory drugs inhibit both the activity and the inflammationinduced expression of acid-sensing ion channels in nociceptors. J Neurosci 21:8026-8033.

Waldmann R, Lazdunski M (1998) H(+)-gated cation channels: neuronal acid sensors in the NaC/DEG family of ion channels. Curr Opin Neurobiol 8:418-424.

Waldmann R, Champigny G, Lazdunski M (1995) Functional degenerincontaining chimeras identify residues essential for amiloride-sensitive $\mathrm{Na}+$ channel function. J Biol Chem 270:11735-11737.

Waldmann R, Champigny G, Bassilana F, Heurteaux C, Lazdunski M (1997a) A proton-gated cation channel involved in acid-sensing. Nature 386:173-177.

Waldmann R, Bassilana F, de Weille J, Champigny G, Heurteaux C, Lazdunski M (1997b) Molecular cloning of a non-inactivating proton-gated $\mathrm{Na}+$ channel specific for sensory neurons. J Biol Chem 272:20975-20978.

Wenzel A, Grimm C, Marti A, Kueng-Hitz N, Hafezi F, Niemeyer G, Reme CE (2000) c-fos controls the "private pathway" of light-induced apoptosis of retinal photoreceptors. J Neurosci 20:81-88. 